\title{
A T2* MRI prospective survey on heart iron in thalassemia major patients treated with deferasirox versus deferiprone and desferrioxamine in monotherapy
}

\author{
Alessia Pepe ${ }^{1 *}$, Antonella Meloni ${ }^{1}$, Giuseppe Rossi ${ }^{1}$, Maria Chiara Dell'Amico ${ }^{1}$, Anna Spasiano ${ }^{2}$, Marcello Capra ${ }^{3}$, \\ Paolo Cianciulli ${ }^{4}$, Vincenzo Caruso ${ }^{5}$, Brunella Favillii, Eliana Cracolici, ${ }^{6}$ Aurelio Maggio ${ }^{7}$, Massimo Lombardi ${ }^{1}$
}

From 2011 SCMR/Euro CMR Joint Scientific Sessions

Nice, France. 3-6 February 2011

\section{Background}

No data are available about the efficacy of the new oral one daily chelator deferasirox on cardiac iron and function versus deferiprone and desferrioxamine. Magnetic Resonance (MR) is the unique non invasive suitable technique to quantitatively evaluate this issue.

\section{Aims}

Our aim was to prospectively assess the efficacy of the deferasirox versus deferiprone and desferrioxamine in monotherapy in a large cohort of thlassemia major (TM) patients by quantitative MR.

\section{Methods}

Among the first $1135 \mathrm{TM}$ patients enrolled in the MIOT (Myocardial Iron Overload in Thalassemia) network, 392 patients performed a MR follow up study at $18 \pm 3$ months according to the protocol. We evaluated prospectively the $193 \mathrm{TM}$ patients who had been received one chelator alone between the 2 MR scans. We identified 3 groups of patients: 80 treated with DFX, 39 treated with DFP and 74 treated with DFO. Myocardial iron concentrations were measured by $\mathrm{T} 2$ * multislice multiecho technique. Biventricular function parameters were quantitatively evaluated by cine images.

"G. Monasterio" Foundation and Institute of Clinical Physiology, CNR, Pisa, Italy

Full list of author information is available at the end of the article

\section{Results}

Excellent/good levels of compliance were similar in the 3 groups (DFX 99\%, DFP 95\%; DFO 96\%, $P=0.6$ ). There were no significant differences in all 3 groups to maintain the patients without significant myocardial iron overload (global heart T2* $\geq 20 \mathrm{~ms}$ ) (DFX 98\%; DFP $100 \%$; DFO 98\%; $\mathrm{P}=1.0$ ). The percentage of patients that maintained a normal LVEF ( $>57 \%)$ was significantly lower in DFX (77\%) versus DFP (100\%) $(\mathrm{P}=0.018)$, it was no significantly different in DFX and DFO group (82\%) ( $\mathrm{P}=0.59)$.

Among the patients with myocardial iron overload at baseline in all 3 groups, there was a significant improvement in the global heart $\mathrm{T} 2 \%$ value and in the number of segment with a normal T2* value; only in the DFP group there was a significant improvement in the right global systolic function $(+6.8 \% P=0.016)$. The improvement in the global heart $\mathrm{T} 2 \%$ was significantly lower in the DFX versus the DFP group $(P=0.0026)$, but it was not significantly different in the DFX versus the DFO group (mean difference global heart T2* $3.5 \pm 4.7 \mathrm{~ms}$ versus $8.8 \pm 8.6 \mathrm{~ms}$ and versus $3.7 \pm 5.5 \mathrm{~ms}$, respectively; $\mathrm{P}=0.90$ ) (Figure 1). The changes in the global systolic biventricular function were not significantly different among groups.

\section{Conclusions}

Prospectively over 15 months in a large clinical setting of TM patients DFP monotherapy was significantly more effective than DFX in improving myocardial siderosis and in maintaining a normal LVEF, no significant 


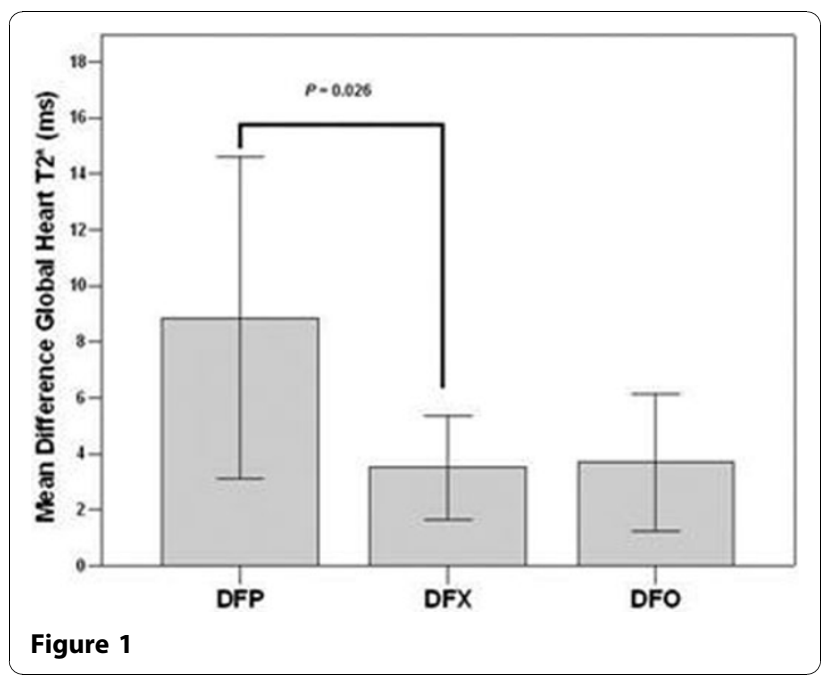

\section{differences were found between DFX and DFO} monotherapy.

\section{Author details}

"'G. Monasterio" Foundation and Institute of Clinical Physiology, CNR, Pisa, Italy. ${ }^{2}$ A.O.R.N. Cardarelli, Napoli, Italy. ${ }^{3}$ Ospedale "G. di Cristina", Palermo, Italy. ${ }^{4}$ Ospedale "Sant'Eugenio Papa", Roma, Italy. ${ }^{5}$ P.O. "S. Luigi-Currò", Catania, Italy. ${ }^{6}$ Policlinico "Paolo Giaccone", Palermo, Italy. ${ }^{7}$ Ospedale "V. Cervello", Palermo, Italy.

Published: 2 February 2011

doi:10.1186/1532-429X-13-S1-O21

Cite this article as: Pepe et al:: A T2* MRI prospective survey on heart iron in thalassemia major patients treated with deferasirox versus deferiprone and desferrioxamine in monotherapy. Journal of Cardiovascular Magnetic Resonance 2011 13(Suppl 1):O21.

Submit your next manuscript to BioMed Central and take full advantage of:

- Convenient online submission

- Thorough peer review

- No space constraints or color figure charges

- Immediate publication on acceptance

- Inclusion in PubMed, CAS, Scopus and Google Scholar

- Research which is freely available for redistribution

Submit your manuscript at www.biomedcentral.com/submit 